\title{
The Influences of Motor Control Adaptation and Human-Equipment Interaction on Issues Related to Golf-Club Design and Optimization
}

\author{
G.B. Shan ${ }^{*}, 1$ N. Betzler ${ }^{2}$ and B. Dunn ${ }^{1}$ \\ ${ }^{I}$ Department of Kinesiology, University of Lethbridge, Canada \\ ${ }^{2}$ School of Life Sciences, Napier University Edinburgh, UK
}

\begin{abstract}
In the current sport-equipment industry, equipment evaluation and/or optimization are mainly done through pure mechanical procedures. It is known that any change of performance environment would cause one to adapt certain aspects of his or her movements to the changed environment. Variation of sport-equipment is counted as an environment change for human performance. Yet, the equipment-induced motor control change is hardly studied and less considered in golf club evaluation/optimization by industries. This study aimed to elaborate on two aspects related to equipmentinduced motor control change using biomechanical analysis of golf swing. The results showed that mechanical variations of clubs did cause significant changes in motor control during golf swings. This would suggest: 1) equipment-induced motor control adjustment would alternate the results of pure mechanical optimization and 2) a reasonable approach for the optimization of golf club should consider both mechanical and biomechanical factors. The results of this study should serve as primary evidence for initiating more and more biomechanical tests related to optimization of golf clubs in sportequipment industry.
\end{abstract}

\section{INTRODUCTION}

Golf is a popular sport discipline that attracts millions of participants worldwide [1]. It is prevalently used as a medium for corporate interactions, providing the greatest opportunity of any sport to private and engaging communications. Due to its popularity and a huge market potential, a wide variety of different golf club designs is available in the market aiming at improving human physical capability in golf, especially for enhancing the efficiency of golf swing. It is believed that some golfers' swing characteristics vary greatly depending on the club they use and that they perform better with certain clubs. Consequently, the majority of golfers choose their equipment with great care; in some regions, individuals invest more than an average of $\$ 790$ on average every year [2]. This number increases dramatically for professional golfers. The total revenue generated from the retail sale of golf related equipment was $\$ 2.5$ billion in 1990 and climbed over $\$ 3$ billion in 2002 [3]. However, in the current club evaluation system, two aspects are hardly considered: 1) human adaptation to equipment (clubs) and 2) humanequipment interactions. These aspects would presumably limit human motor ability and/or change human motor control, which should be taken into account in equipment design \& optimization.

One may/can adapt certain aspects of his or her movements to changing characteristics in the performance environment [4]. Based on this theory, it is reasonable to assume that skillful golfers are able to adapt their swing to changes in equipment variables, and that these adaptations could lead

*Address correspondence to this author at the Department of Kinesiology, University of Lethbridge, 4401, University Drive, Lethbridge, Alberta, Canada, TIK 3M4, Canada; Tel: 1-403-329-2683; Fax: 1-403-380-1839;

E-mail: g.shan@uleth.ca to performance effects in individual golfers. However, golf clubs are often designed using an engineering approach focusing on mechanical club properties and launch data [5]. To this end, the industry is currently doing much research on the design of golf clubs, such as varying their shaft length and elasticity, center of mass and club head surface properties [6, 7]. While these efforts address well the mechanical aspects of a golf swing, they fail to take into consideration the human factor, the biomechanical components. As the development of Human Factors and Ergonomics is now focused on biological enhancement [8], the design and evaluation of the effectiveness of any initiative equipment should be supported by quantitative evidences obtained through both mechanical and bio-science. Recently, more and more biomechanics methods including motion analysis and electromyography (EMG) are applied in Applied Ergonrmics studies for evaluation of professional footwear, computer equipments and injuries related to workload [9-12]. This trend should be implemented/initiated into the golf club industry as well.

Currently, it appears that it is not yet possible to consider the motor skill adaptation and interaction between the player and the club when designing or fitting clubs [13]. The results of previous studies on golf swing using human subjects are mainly focused on the influences of different club types on a swing, such as kinematic characteristics of 5-iron, 7-iron, 9iron, a driver and pitching-wedge $[14,15]$, or threedimensional trunk range of motion for driver and 7-iron swings [16]. Few authors reported the effect of changes in club properties within one type of clubs on body movement characteristics. It was found that golfers did not change their stance when swinging 5-irons that only differed in shaft stiffness [17]. In contrast to this, players did adapt their swing to increases in driver shaft length with an increased feet-to-ball distance, thereby avoiding changes in their body posture [18]. In terms of trunk rotation, neither changes in 
shaft stiffness [17] nor club length [18] had a marked effect on hip and shoulder rotation. Possibly, the player's adaptation strategy included changes in wrist movement rather than shoulder or pelvis kinematics. Additionally, temporal swing characteristics such as swing tempo remained unchanged when driver club length was varied [18]. In summary, more evidences for proving control adaptation are needed.

Kinetics, or more specifically, ground reaction force measurement, on the other hand, has been successfully used in the past to examine weight shift patterns of beginner and/or advanced golfers during the swing $[19,20]$. Nevertheless, it should be mentioned that the force platform data captured was unable to separate the effects of the club from those of the body. In other words, the data represented the weight transfer patterns of the golfer with the golf club - an effect of the joint body-club system. To the best of our knowledge, there is no study dealing with the dynamic influence of the club alone on the golfers' weight transfer or the golfers' control strategies during a golf swing movement.

An understanding of how players adapt their body movement to different golf clubs and/or the interaction between human body and club could potentially aid club design and support the club fitting process. To the authors' best knowledge, except for studies on iron shaft stiffness effects [17] and driver club length [18], little research has been published that quantifies the effects of design alterations of a single club type on the kinematics of upper body movement. As well, no recorded research on the influences of body-club interaction on club swing control was found. The mechanical interaction between the player and the club used is related to the moment and forces the two systems exchange with each other. Most likely, both the clubs' and the human's response will change depending on the equipment used, such as how is the club's effect on human motor response. Presumably, these two aspects should be relevant for sport equipment evaluation and/or optimization. Therefore, this study tried to bridge the gaps by addressing these two missing links. The specific aims of the study were 1) to identify whether a group of golfers adapted their upper body movement to small changes in the properties of a single club type (6-Iron) and 2) to quantify the body-club interaction by comparing swings with a Driver and 7-Iron.

\section{METHOD}

\section{Subjects and Test Clubs}

A group of 5 right-handed, advanced golfers voluntarily participated in this study (mean characteristics \pm standard deviation: handicap $4.8 \pm 3.7$, age $31.8 \pm 8.7$ years, height $1.81 \pm 0.04 \mathrm{~m}$, and body mass $94.26 \pm 11.2 \mathrm{~kg}$ ). The Human Subjects Research Committee of the University of Lethbridge scrutinized and approved this protocol as meeting the criteria from the Tri-Council Policy Statement: Ethical Conduct for Research Involving Humans, from the Natural Sciences \& Engineering Research Council. All subjects in the study were informed of the testing procedures. They signed an approved consent form and voluntarily participated in the data collection.

For identification of motor skill adaptation, the 6-iron clubs were selected to represent a typical sample of commercially available 6 -irons with shaft lengths ranging from 37 " to 38 " and swing weights ranging from C9.7 to D5.0 (see Table 1). For quantification of body-club interaction, a driver and 7-iron were used.

Table 1. List of 6-Iron Clubs Tested

\begin{tabular}{|c|c|c|}
\hline Club ID & Length (“) & Swing Weight \\
\hline \hline $\mathrm{I} 01$ & $37^{1 / 2}$ & $\mathrm{D} 0.6$ \\
\hline $\mathrm{I} 02$ & $37^{1 / 4}$ & $\mathrm{D} 0.2$ \\
\hline $\mathrm{I} 03$ & $37^{1 / 2}$ & $\mathrm{D} 0.3$ \\
\hline $\mathrm{I} 05$ & $37^{3 / 4}$ & $\mathrm{C} 9.7$ \\
\hline $\mathrm{I} 06$ & 37 & $\mathrm{D} 1.8$ \\
\hline $\mathrm{I} 09$ & $37^{1 / 2}$ & $\mathrm{D} 0.0$ \\
\hline $\mathrm{I} 13$ & $37^{1 / 2}$ & $\mathrm{D} 2.0$ \\
\hline $\mathrm{I} 14$ & $37^{1 / 2}$ & $\mathrm{D} 2.3$ \\
\hline $\mathrm{I} 15$ & $37^{1 / 4}$ & $\mathrm{D} 1.5$ \\
\hline $\mathrm{I} 16$ & 38 & $\mathrm{D} 5.0$ \\
\hline
\end{tabular}

\section{Test Procedure}

Subjects were allowed to perform a sufficient number of warm up swings to get used to the test environment. After warm-up, they performed 3 good golf swings with each club. Each subject decided on his own pacing between warm up and tests, so that the individual's optimal motor control pattern could be measured. Golf balls were placed on an artificial golf mat $\left(2 \times 2 \mathrm{~m}^{2}\right)$ used to mimic the effects of grass. Subjects stood on the force platforms and hit the ball towards a huge vertically-hanging curtain with dimensions of $7 \times 7 \mathrm{~m}^{2}$. The use of this impact-absorbing curtain reduced rebound. Aside from making subjects more comfortable, this had the added advantage of preventing equipment damage. During each swing, the kinematic (3D motion capture) and kinetic (Ground Reaction Force) data were captured simultaneously. We placed no restrictions on the subjects before and during the trials in an effort to preserve their normal motor control style.

\section{Kinematic Swing Variables}

In order to quantitatively determine the whole body kinematic characteristics during a swing, 3D motion capture was used (Fig. 1a). Specifically, a twelve-camera VICON v8i motion capture system (Oxford Metrics Ltd., Oxford, England) gathered kinematic data from the subjects. Capture occurred at a rate of 250 frames/second with the VICON software (Science \& Engineering Software Suite, 2002) triangulating positions of each marker and rendering them in three-dimensional computer space. Calibration residuals were determined in accordance with VICON's guidelines and yielded positional data accurate within $1 \mathrm{~mm}$. Each of the subjects wore a black garment made of stretchable material, which covered the upper and lower body. Affixed to the garment were 42 reflective markers, each with a diameter of $9 \mathrm{~mm}$. They were placed on the anterior superior iliac crest, posterior superior iliac crest, lateral condyle of the tibia, lateral malleolous of the fibula, calcaneal tuberosity, tuberosity of the fifth metatarsal and the head of hallicus, as well as on 
the upper and lower leg. Markers on the upper body were placed on the acromion process, lateral epicondyle of the humerus, styloid process of the ulna and radius, third metacarpophalangeal joint, as well as the upper and lower arm, sternal notch, xiphoid process, C7, T10 and left and right back. Four markers were also placed on the head - one each on the left and right temples and two on the posterior portion of the parietal bone. The markers as shown in Fig. (1b) reflect infrared light to the cameras positioned around the subject. All trajectories of the body markers were filtered using a low pass Butterworth filter with a cut-off frequency of 10 $\mathrm{Hz}$ (as used in previous golf studies by Coleman \& Rankin [21]; Wheat, Vernon \& Milner [22]). From these 42 markers, a full body biomechanical model with 15 segments (Fig. 1c) was built to determine the transfer of centre of gravity (COG) or COG excursion range. The model worked as fol- lows: from motion capture, we could establish anatomical positions, which then allowed the construction of a 15segment full-body model. In such individualized biomechanical modeling, the anthropometric characteristics of the body were established using anthropometric regression equations found through statistical studies [23]. The fifteen segments were head \& neck, upper trunk, lower trunk, two upper arms, two lower arms, two hands, two thighs, two shanks and two feet. In addition, markers were attached on the shaft (one) and the head (two) of the club to establish club orientation and club head speed.

Three-dimensional thoracic rotation was defined following the Cardan approach as described by Wheat et al. [22]. This method describes upper body rotation based on a Cardan sequence defining the position of a local thorax coordinate system relative to the global lab coordinate system.

a)

(12)

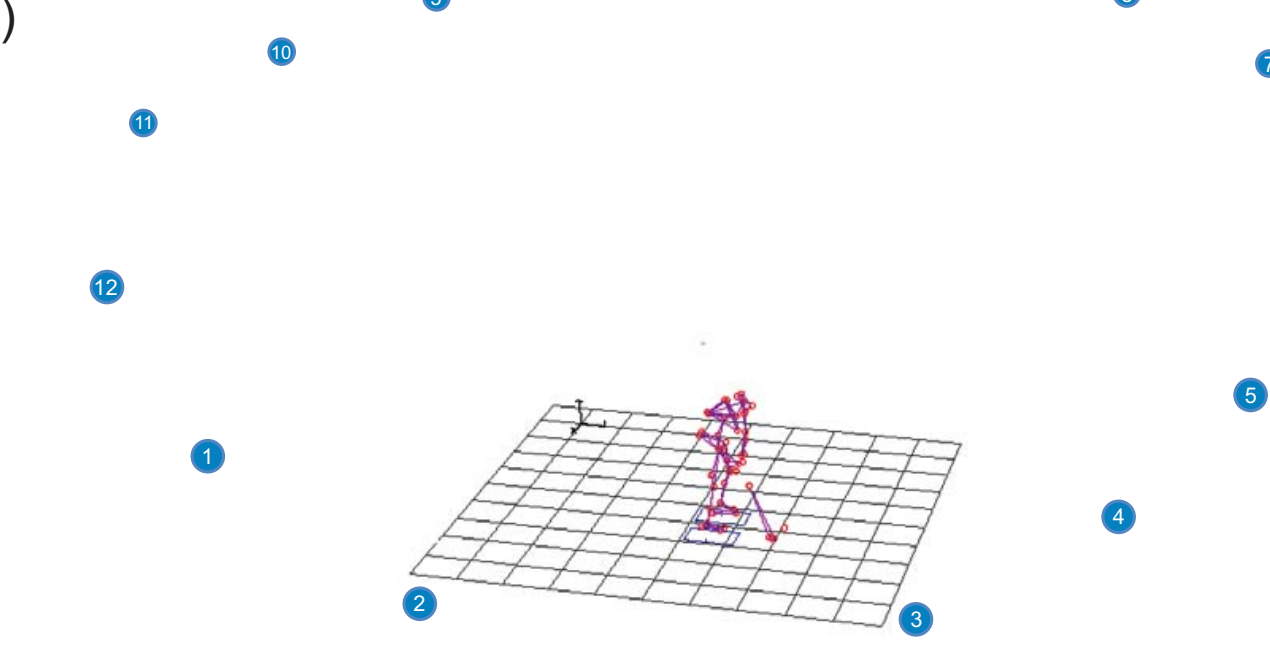

b)

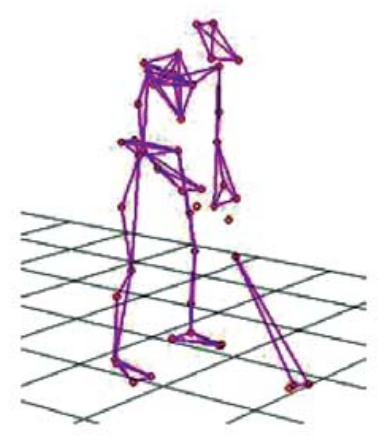

c)

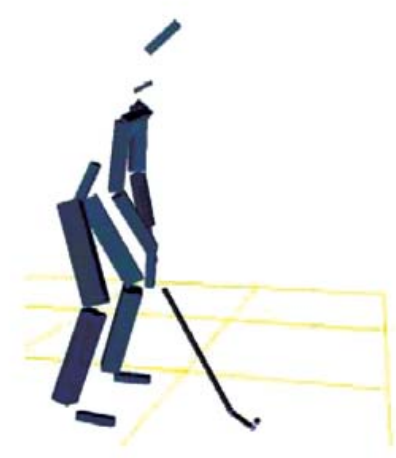

Fig. (1). (a) set-up of the synchronized measuring system, (b) Exemplars raw data and (c) model after performing model calculation. 
The thorax coordinate system was defined from the position of the xiphoid, sternum, C7 and T10 markers, with the xiphoid marker being only used to define the coordinate system but not to track the motion [22]. This method was chosen because it avoids determining torso rotation from a simplified, projected two-dimensional vector and is not based on markers placed on the acromion processes, which have been found to move independently from the thorax under certain conditions [24]. Pelvis rotation was defined in a similar way using the four markers placed on the iliac crest of the pelvis. Again following the suggestions from Wheat et al. [22], the order of all Cardan sequences was Z-X-Y, with the Z-axis pointing upwards towards the head of the player, the $\mathrm{x}$-axis pointing frontally and the $y$-axis pointing laterally to the left of the subject. This study focused on z-axis rotations, which were negative when the subject turned away from the target, zero when the y-axis of the local coordinate system was parallel to the target line and positive when the subject turned towards the target.

\section{Temporal Swing Variables}

For each trial, three events were identified: take away (onset of club-head motion), transition from backswing to downswing (peak pelvis rotation away from the target) and impact (first frame in which ball movement occurred). Following common golf terminology, swing tempo was defined as the ratio between backswing and downswing rotation.

\section{Ground Reaction Force Measurement}

Two KISTLER force platforms were used to capture the weight transfer during a golf swing under each foot (excursion range). It should be noted that the captured data known as Center of Ground Reaction Force (CGRF) - were combined to reveal the transfer patterns of the golfer-club system (a joint effect). By comparing the dynamic CGRF to the dynamic COG, which represents the golfer-only system, the effects of club on swing techniques (separation of COG and CGRF) can be quantified and revealed.

\section{Statistical Analysis}

To identify whether there were any significant differences in temporal or kinematic swing variables depending on the club used, the trials of all subjects were pooled and analyzed using a Kruskal-Wallis test with club ID as grouping variable and the temporal and kinematic variables at the key events as test variable. This test is the nonparametric equivalent of an analysis of variance (ANOVA) and does not assume the data to be normally distributed. It was chosen due to the small number of samples. If the Kruskal-Wallis test found significant variations in a variable depending on the club used, results for this variable were split into two groups defined by the swing weight of the clubs (swing weight $<$ D1.5 or $\geq$ D 1.5) for exploration of motor skill adaptation or club type (Driver or 7-Iron) for quantification of body-club interaction. Comparisons between results from two groups were preformed using a Mann-Whitney U test, which is the nonparametric equivalent of a T-test. All statistical procedures were performed using SPSS (SPSS Inc., USA) with an alpha level of 0.05 .

\section{RESULTS}

\section{Temporal Swing Characteristics}

Table 2 summarises the temporal characteristics of the pooled results from all subjects. No significant differences were found in terms of backswing duration $(\mathrm{P}=0.286)$, downswing duration $(\mathrm{P}=0.95)$ or swing tempo $(\mathrm{P}=0.247)$

Table 2. Temporal Swing Characteristics. Mean, S.D. and S.E. are Representative for All Swings Performed by All Subjects. Club Effects Indicates Whether there was Any Difference Depending on the Club Used

\begin{tabular}{|c|c|c|c|c|}
\hline Variable & Mean & S.D. & S.E. & Club Effects \\
\hline \hline Backswing duration (s) & 0.87 & 0.21 & 0.015 & not sign. \\
\hline Downswing duration (s) & 0.35 & 0.04 & 0.003 & not sign. \\
\hline Swing tempo & 2.56 & 0.75 & 0.054 & not sign. \\
\hline
\end{tabular}

\section{Thorax and Pelvis Rotation}

The Kruskal-Wallis test indicated that there were significant differences within the pooled club results for all torso and pelvis rotation variables ( $\mathrm{P}<0.001$ in all cases), indicating that the subjects as a group adjusted their swing motion depending on the club used (see Table 3). To further investigate possible reasons or patterns within these results, the test clubs were split into two groups depending on their swing weight. It was found that both thorax and pelvis rotation differed significantly between swings performed with clubs from the two swing weight groups $(\mathrm{P}<0.001$ for all variables). The resulting mean thorax and pelvis angles for each group at take away, transition and impact are displayed in Fig. (2). It can be seen that, on average, subjects rotated away from the target to a more closed position when swinging clubs with swing weights $>$ D1.5.

Table 3. Thorax and Pelvis Angles at Key Swing Events

\begin{tabular}{|c|c|c|c|c|c|}
\hline Variable & Event & Mean & S.D. & S.E. & Club Effects \\
\hline \hline \multirow{3}{*}{$\begin{array}{c}\text { Thorax } \\
\text { rotation }\end{array}$} & Take-away & $3.16^{\circ}$ & $4.66^{\circ}$ & $0.34^{\circ}$ & sign., $\mathrm{P}<.001$ \\
\cline { 2 - 6 } & Transition & $-74.86^{\circ}$ & $15.43^{\circ}$ & $1.10^{\circ}$ & sign., $\mathrm{P}<.001$ \\
\cline { 2 - 6 } & Impact & $7.48^{\circ}$ & $6.34^{\circ}$ & $0.45^{\circ}$ & sign., $\mathrm{P}<.001$ \\
\hline \multirow{2}{*}{$\begin{array}{c}\text { Pelvis } \\
\text { rotation }\end{array}$} & Take-away & $4.89^{\circ}$ & $3.98^{\circ}$ & $0.28^{\circ}$ & sign., $\mathrm{P}<.001$ \\
\cline { 2 - 6 } & Transition & $-43.63^{\circ}$ & $12.77^{\circ}$ & $0.91^{\circ}$ & sign., $\mathrm{P}<.001$ \\
\cline { 2 - 6 } & Impact & $25.88^{\circ}$ & $8.59^{\circ}$ & $0.61^{\circ}$ & sign., $\mathrm{P}<.001$ \\
\hline
\end{tabular}

\section{Body-club Interaction During Swings}

3-D motion analysis and CGRF results revealed distinguishable differences of club swing between using a Driver and 7-Iron. Even though both clubs showed that no significant difference existed for down swing duration ( $p>0.05$ ), it was found that the Driver caused more a) excursion range and b) separation of COG and CGRF than 7-Iron in both 


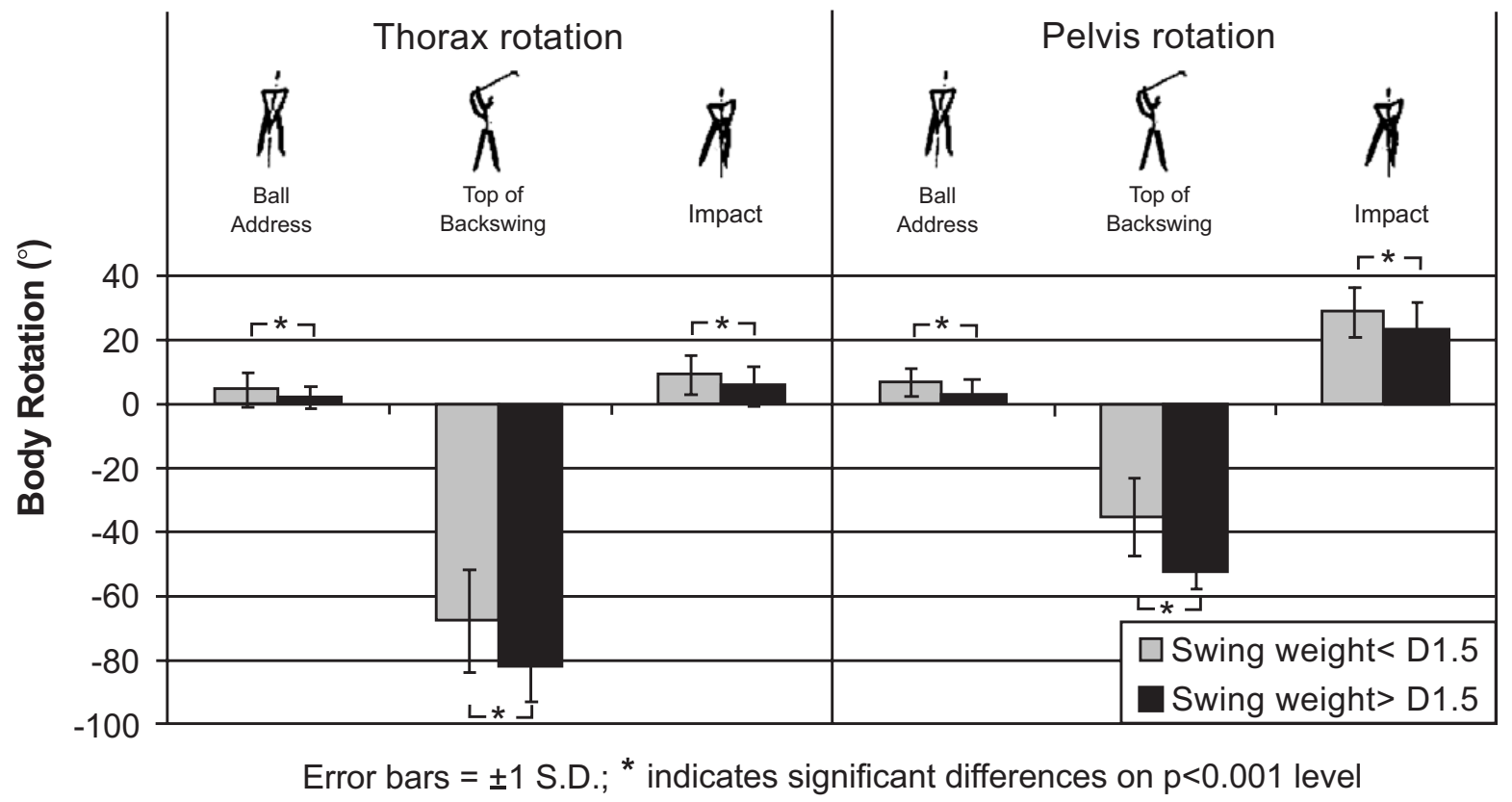

Fig. (2). Mean torso and pelvis rotation at key events for swings performed with clubs with swing weights greater and smaller than D1.5. Asterisks indicate significant differences on $\mathrm{p}<.001$ level.

medial-lateral (M-L) and anterior-posterior (A-P) directions during COG and CGRF excursions $(\mathrm{p}<0.01$, Fig. 3 and Table 4). Further more, the typical weight transfer diagram (Fig. 3) indicated that both COG and CGRF transferred more in the M-L direction than in the A-P for using both Driver and 7Iron clubs $(p<0.05)$. The weight transfer diagram also revealed that the left foot carried more weight than the right one during a swing and forefeet were assigned more load than rear feet, regardless of the club type $(p<0.05)$.

\section{DISCUSSIONS}

The purposes of this study were to elaborate on the influences of biomechanical/human tests on golf club evaluation/optimization. The specific aim was to demonstrate pos- sible effects of two biomechanical phenomena - motor control adaptation and body-equipment interaction - on this issue, because these two aspects appear to be underemphasized in golf club design, evaluation and optimization.

The first part of the study was to investigate whether a group of golfers adapted their thorax and pelvis movement when swinging 6-irons with varying mechanical properties. It was found that backswing and downswing duration were not affected, which is in agreement with previous studies comparing different types of clubs $[14,15]$ and with varying shaft lengths [18]. As these studies showed that golfers were able to apply similar swing timing even when swinging different types of clubs, it is not surprising that relatively small differences in club properties did not have an effect in the

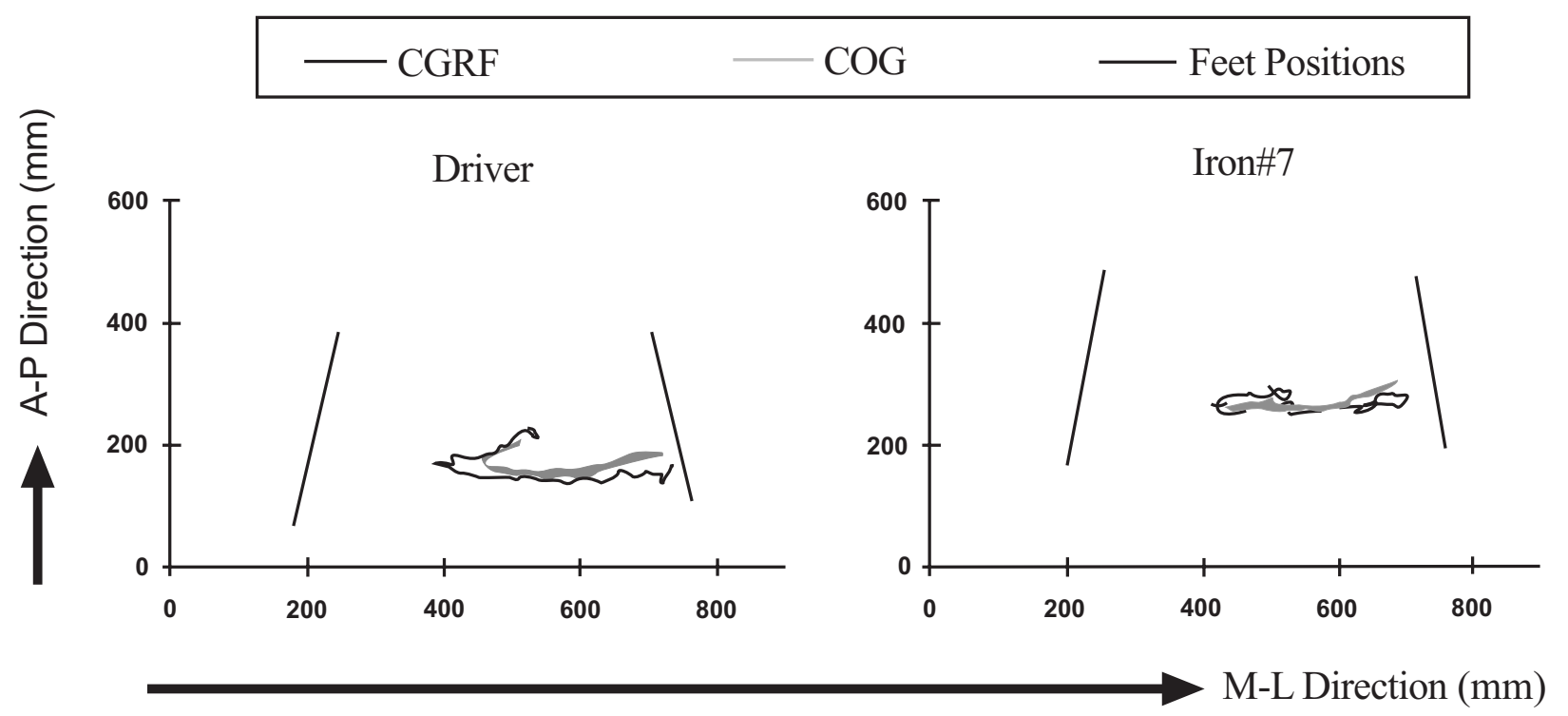

Fig. (3). Typical excursions of CGRF and COG during swings using Driver and 7-Iron. 
present study. Although adaptation did not occur from a timing perspective, there was adaptation in segments' coordination. Golfers as a group altered their thorax and pelvis control depending on which club was used. In an attempt to identify which mechanical club variable caused these effects, swings were split into two swing weight groups. It was found that there was a systematic difference between these two groups (Fig. 2). This difference does not necessarily imply a causal relationship between body rotation and swing weight. Whilst the order of clubs was randomised, it is still possible that fatigue had an effect on the results, and future studies should consider testing subjects repeatedly with varying club order to control for this. Since this study has established that thorax and pelvis rotation can be affected by alterations in club parameters within one club type, more systematic studies are needed in which only one club parameter is changed at a time over a wider range than in the present study. Ideally, these studies should be performed on the field, opposed to lab based studies where the ball is hit in a net do not allow the golfer to focus on a realistic target. Despite the possible improvements described above, this study successfully demonstrated that it is possible to measure body motion adjustments even when clubs are of the same type and have very similar properties.

Table 4. The Influences of Club Type on COG-CGRF Separation

\begin{tabular}{|c|c|c|}
\hline \multirow{2}{*}{} & \multicolumn{2}{|c|}{ Max. Separation (mm) } \\
\cline { 2 - 3 } & M-L & A-P \\
\hline \hline Driver & $35 \pm 17$ & $28 \pm 9$ \\
\hline \#7 Iron & $7 \pm 11$ & $20 \pm 8$ \\
\hline Club effects & sign., $\mathrm{P}<.001$ & sign., $\mathrm{P}<.01$ \\
\hline
\end{tabular}

The second part of the study explored the effect of bodyequipment interaction on motor skill control. The results indicated that the balance control in M-L direction is more relevant than that in A-P direction. This supports previous studies on centre of mass displacement in golfers [25]. As far as the club type was concerned, the larger range of excursion using a Driver as well as more COG and CGRF separation revealed that a Driver had more influence on the golfer's weight transfer (dynamic balancing) than the iron in both A$\mathrm{P}$ and $\mathrm{M}-\mathrm{L}$ directions. For some golfers, the increased influence would put them into a challenging state of dynamic balancing control, as CGRF excursion approached the limit of their supporting base marked by the feet (Fig. 2, A-P direction).

The relevant implication obtained from this study is that the evaluation and/or optimization of sport equipment should relate to both mechanical and human aspects. The equipment-induced motor control adjustment would alternate the results of pure mechanical optimization. Since human motor control strategies cover a certain range of biological variation depending on factors such as age, experience and performance level, one should adapt certain aspects of his or her movements to changing characteristics in the performance environment [4]. This makes biomechanical testing more relevant to sport equipment optimization. Without a thor- ough understanding of interaction between equipment alteration and human motor control adaptation, equipment optimization would be like a hit-and-miss game. Based on current understanding, the following relationship among mechanical, biomechanical design/test and club evaluation/optimization is proposed in Fig. (4). Biomechanical test should function as a bridge between mechanical engineering and product/ equipment optimization. Specifically, biomechanics should supply important feedbacks for equipment optimization: 1) anthropometry would supply physical limitations of equipment to a motor skill related to age, gender, and/or race [26] and 2) motor control adaptation and body-equipment interaction would provide equipment-induced motor control change mainly related to performance level. The results of the current study should serve as primary evidence for approaching the optimization using both bio- and mechanical aspects.

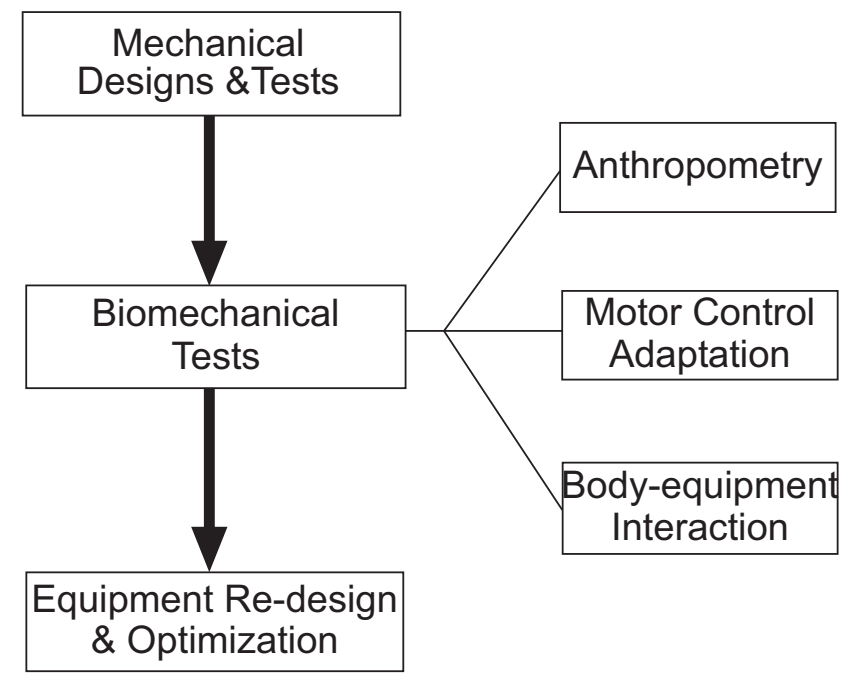

Fig. (4). Biomechanical test as a bridge between mechanical design/test and equipment re-design/optimization.

\section{CONCLUSION}

This study can be seen as a first step towards a better understanding of body-equipment interaction and body movement adjustments of players to different club designs. It shows that it is worthwhile to include considerations on body movement adaptation in the club design or fitting process because even small changes in mechanical club properties appear to be detected and are adjusted for by advanced players. To reach the goal of club optimization, biomechanical tests should be induced by the sport equipment industry in its equipment evaluation/optimization in addition to its exiting mechanical process.

\section{ACKNOWLEDGEMENT}

This work was supported by National Science and Engineering Research Council of Canada (NSERC), Sport Science Association Alberta (SSAA, Canada) and Westgrid (Canada).

\section{REFERENCES}

[1] Proctor S. Economic contribution of golf to the UK economy. Thain E, Ed. Science and Golf IV. London: Routledge 2002.

[2] Victorian Golf Association. How much do people spend on organised golf in Australia? Retrieved from the website of the Victorian Golf Association; 2006 [2007 June 21] available from: 
http://www.golfvic.org.au/Content/NavigationMenu/Information/Si zeoftheGolfIndustry/Si e_and_Economic_Impact/Size-and-ScopeStudy-June-2006.pdf.

[3] U.S. Census Bureau. Statistical Abstract of the United States: Sporting goods Sales by Product Category: 1990 to 2003. Washington, D.C.: U.S. Census Bureau, 2004, Table 147.

[4] Magill RA. Motor learning: concepts and applications (6 ${ }^{\text {th }}$ Edition). Boston: McGraw Hill 2001.

[5] Chou A. Engineering Methodology in Golf Studies. Hung GK, Pallis JM Ed. Biomedical engineering principles in sports. New York: Kluwer 2004.

[6] Cheong SK, Kang KW, Jeong SK. Evaluation of the mechanical performance of golf shafts. Eng Fail Analys 2006; 13, 464-73.

[7] Choi YC, Hong SI. Mechanical properties and microstructure of commercial amorphous golf club heads made of $\mathrm{Zr}-\mathrm{Ti}-\mathrm{Cu}-\mathrm{Ni}-\mathrm{Be}$ bulk metallic glass. Mater Sci Eng A 2007; 449-451: 126-29.

[8] Boff KR. Revolutions and shifting paradigms in human factors \& ergonomics. Appl Ergon 2006; 37(4): 391-9.

[9] Chiu M, Wang MJ. Professional footwear evaluation for clinical nurses. Appl Ergon 2007; 38(2): 133-41.

[10] Flodgren G, Heiden M, Lyskov E, Crenshaw AG. Characterization of a laboratory model of computer mouse use-Applications for studying risk factors for musculoskeletal disorders. Appl Ergon 2007; 38(2): 213-8.

[11] Knight JF, Baber C. Assessing the physical loading of wearable computers. Appl Ergon 2007; 38(2): 237-47.

[12] Village J, Frazer M, Cohen M, Leyland A, Park I, Yassi A. Electromyography as a measure of peak and cumulative workload in intermediate care and its relationship to musculoskeletal injury: An exploratory ergonomic study. Appl Ergon 2005; 36(5): 609-18.

[13] Farrally MR, Cochran AJ, Crews DJ, et al. Golf science research at the beginning of the twenty-first century. J Sports Sci 2003; 21(9): $753-65$.

[14] Egret CI, Vincent O, Weber J, Dujardin FH, Chollet D. Analysis of 3D kinematics concerning three different clubs in golf swing. Int $\mathrm{J}$ Sports Med 2003; 24(6): 465-70.
[15] Neal R, Abernethy B, Moran M, Parker A. The influence of club length and shot distances on the temporal characteristics of the swings of expert and novice golfers. Cochran A. Ed. Science and Golf: Proceedings of the First World Scientific Congress of Golf. London: E \& FN Spon 1990.

[16] Lindsay DM, Horton JF, Paley RD. Trunk motion of male professional golfers using two different golf clubs. J appl biomech 2002; 18(4): 366-73.

[17] Wallace ES, Hubbell JE. The effect of golf club shaft stiffness on golf performance variables - implications for club-fitting. Proceeding of Materials \& Science in Sports Symposium; 2001 Apr 22-25; Coronado Island Marriott Resort, Coronado, California, USA.

[18] Wallace ES, Hubbell JE, Rogers MJ. Driver shaft length influences on posture and swing tempo in skilled golfers. Hubbard M, Mehta, RD, Pallis JM, Ed. The Engineering of Sport 5 Sheffield: ISEA 2004.

[19] Koslow R. Patterns of weight shift in the swing of beginning golfers. Percep Motor Skills 1994; 79: 1296-98.

[20] Richards J, Farrell M, Kent J, Kraft R. (1985). Weight transfer patterns during the golf swing. Res Q Exerc Sport 1985; 56:361-5.

[21] Coleman SGS, Rankin AJ. A three-dimensional examination of the planar nature of the golf swing. J Sports Sci 2005; 23(3): 227-34.

[22] Wheat JS, Vernon T, Milner CE. The measurement of upper body alignment during the golf drive. J Sports Sci 2007; 25(7): 749 - 55.

[23] Shan GB, Bohn C. Anthropometrical data and coefficients of regression related to gender and race. Appl Ergon 2003; 34: 327-37.

[24] Elliott B, Wallis R, Sakurai S, Lloyd D, Besier T. The measurement of shoulder alignment in cricket fast bowling. J Sports Sci 2002; 20(6): 507-10.

[25] Burden AM, Grimshaw PN, Wallace ES. Hip and shoulder rotations during the golf swing of sub-10 handicap players. J Sports Sci 1998; 16: 165-76.

[26] Shan GB, Bohn C, Sust M, Nicol K. How can dynamic rigid-body modeling be helpful in motor learning? - Learning performance through dynamic modeling. Kinesiology 2004; 36(2): 182-91.

(C) Shan et al.; Licensee Bentham Open.

This is an open access article distributed under the terms of the Creative Commons Attribution License (http://creativecommons.org/license/by/2.5/), which permits unrestrictive use, distribution, and reproduction in any medium, provided the original work is properly cited. 